\title{
LEITE CRU DE QUATRO REGIÕES LEITEIRAS BRASILEIRAS: PERSPECTIVAS DE ATENDIMENTO DOS REQUISITOS MICROBIOLÓGICOS ESTABELECIDOS PELA INSTRUÇÃO NORMATIVA $51^{1}$
}

\author{
Luís Augusto NERO ${ }^{2, *}$, Marcos Rodrigues de MATTOS $^{3}$, Vanerli BELOTI ${ }^{3}$, Márcia de A. F. BARROS ${ }^{3}$, José
}

\begin{abstract}
Paes de A. N. PINTO ${ }^{4}$, Nélio José de ANDRADE ${ }^{5}$, Wladimir Padilha da SILVA ${ }^{6}$, Bernadette D. G. M. FRANCO ${ }^{2, *}$ RESUMO

Evidências que o leite produzido e consumido no Brasil nem sempre apresenta a qualidade desejada têm gerado a discussão e desenvolvimento de novas politicas de incentivo à produção leiteira, resultando no desenvolvimento do Programa Nacional de Melhoria da Qualidade do Leite. Em complementação, em 2002 o Ministério da Agricultura publicou a Instrução Normativa 51 (IN51), com importantes inovações em relação à conservação e transporte do leite cru, além de estabelecimento de um padrão de qualidade para esse tipo de leite $\left(10^{6} \mathrm{UFC} / \mathrm{mL}\right)$, a ser implantado em diferentes prazos nas diferentes regiões do país, a partir de 2005 . $\mathrm{O}$ presente trabalho teve como objetivo verificar se o leite cru produzido em quatro áreas de quatro estados produtores de leite no Brasil estaria, nesse momento, em condições de cumprir o estabelecido na IN 51, especialmente quanto ao atendimento dos padrões microbiológicos previstos. Amostras de leite cru, coletadas em 210 diferentes propriedades nas regiões de Viçosa, MG (47), Pelotas, RS (50), Londrina, PR (63) e Botucatu, SP (50), foram analisadas quanto aos niveis de contaminação por aeróbios mesófilos, utilizando o Petrifilm ${ }^{\mathrm{TM}}$ AC. Parcela significativa das amostras (48,6\%) apresentaram contagens acima do determinado pela IN51, sendo 21,3\% na região de Viçosa (MG), $56,0 \%$ na região de Pelotas (RS), 47,6\% na região de Londrina (PR) e 68,0\% na região de Botucatu (SP). Considerando as diferenças de cada região, foi possivel observar a importância da refrigeração na conservação e transporte da produção, bem como da implantação de boas práticas e assistência técnica nas propriedades. Os resultados obtidos permitem concluir que a adequação às normas estabelecidas pela IN51 pode ser mais dificil em algumas regiões do que em outras, sendo fundamental a adoção da refrigeração na conservação e no transporte da produção, e de programas regionais de assistência a produtores leiteiros.

Palavras-chave: leite cru; qualidade; legislações; IN51.
\end{abstract}

\section{SUMMARY}

RAW MILK FROM FOUR BRAZILIAN MILK-PRODUCING STATES: PERSPECTIVES OF COMPLIANCE WITH THE MICROBIOLOGICAL CRITERIA ESTABLISHED BY THE INSTRUÇÃO NORMATIVA 51. The need to improve quality and safety of milk produced and consumed in Brazil resulted in development of new governmental policies to support the Brazilian milk-producing sector. Among them, the most relevant is the PNMQL (National Program to Improve Milk Quality). In 2002, the Brazilian Ministry of Agriculture created the Instrução Normativa 51 (Normative Instruction 51, IN51), with important innovations related to maintenance and transport of raw milk, besides establishment of microbiological standards to be implemented in different periods of time, according to the producing region, starting in 2005. The present study aimed to trace if raw milk produced in four important milk-producing regions in the country would be capable to be in accordance to the microbiological standards established by IN51. Raw milk samples, collected in 210 different milk-producing farms, located in vicinities of Viçosa (Minas Gerais state), Pelotas (Rio Grande do Sul state), Londrina (Paraná state) and Botucatu (Sao Paulo state) were submitted to counts of mesophilic aerobes using Petrifilm ${ }^{\mathrm{TM}} \mathrm{AC}$ plates. In a significant number of samples, the counts were above the standards, being $21.3 \%$ from Viçosa, $56.0 \%$ from Pelotas, $47.6 \%$ from Londrina and $68.0 \%$ from Botucatu. Taking into account the differences in milk-producing practices adopted in the four regions, the study evidenced the importance of cooling during maintenance and transport of raw milk. The relevance of adoption of good hygiene practices and access to technical support was also evidenced. The conclusion of the study is that the difficulties to achieve the standards established by IN51 may vary from region to region. Cooling of milk for maintenance and transport is fundamental, but regional programs to assist the milk producers are also needed.

Keywords: raw milk; quality; regulations; IN51

\section{1 - INTRODUÇÃO}

Considerando as evidências que o leite produzido e consumido no Brasil nem sempre apresenta a qualida-

\footnotetext{
Recebido para publicação em 17/05/2004. Aceito para publicação em 28/12/2004 (001345).

2. Depto. de Alimentos e Nutrição Experimental, Faculdade de Ciências Farmacêuticas, Universidade de São Paulo, Av. Prof. Lineu Prestes, 580, CEP 05508-900, São Paulo, SP, Brasil. E-mails: bfranco@usp.br; luisnero@yahoo.com.br

${ }^{3}$ Laboratório de Inspeção de Produtos de Origem Animal, Depto. de Medicina Veterinária Preventiva, Universidade Estadual de Londrina, Londrina, $P R$.

${ }^{4}$ Depto. de Higiene de Alimentos e Inspeção, UNESP, Botucatu, SP.

${ }^{5}$ Depto. de Tecnologia de Alimentos, Universidade Federal de Viçosa, Viçosa, $M G$.

${ }^{6}$ Depto. de Ciência e Tecnologia Agroindustrial, Universidade Federal de Pelotas, Pelotas, RS.

* A quem a correspondência deve ser enviada.
}

de desejada $[1,2,3,10,11,16,17,18,20,21,24,25]$, o Ministério da Agricultura do Brasil iniciou há cerca de 10 anos uma discussão nacional, envolvendo os setores científicos e econômicos do setor leiteiro, buscando alternativas para melhorar a qualidade do leite produzido no país. Essa discussão resultou na Portaria ${ }^{\circ}$ 166 [4], que estabeleceu um grupo de trabalho para analisar e propor um programa de medidas visando o aumento da competitividade e a modernização do setor leiteiro no Brasil. Esse grupo desenvolveu uma versão do Programa Nacional de Melhoria da Qualidade do Leite (PNMQL), projeto que já vinha sendo desenvolvido desde 1996, e o submeteu à consulta pública pela Portaria ${ }^{\circ}$ 56 [5]. A versão definitiva das novas normas de produção leiteira foi publicada na Instrução Normativa ${ }^{\circ} 51$ (IN51), de 18 de setembro de 2002, que determina novas normas na produção, identidade e qualidade de leites tipos A, B, C, pasteurizado e cru refrigerado, além 
de regulamentar a coleta de leite cru refrigerado e seu transporte a granel [6]. Outro incentivo à modernização da produção leiteira no Brasil ocorreu em 2003, pela Resolução $n^{\circ} 3088$ [7], que aprovou financiamento de equipamentos de resfriamento e coleta a granel para produtores de leite. A principal razão de todas essas medidas foi a necessidade de adequação das normas publicadas no RIISPOA [8] às atuais realidades de produção e consumo de leite no Brasil.

Dentre as modificações preconizadas pela IN51, pode ser citada a permissão de comercialização de leites pasteurizados tipos A e B com diferentes percentagens de gordura (integral, padronizado, semidesnatado e desnatado), visando atender um mercado consumidor cada vez mais crescente. Entretanto, uma das principais alterações diz respeito ao leite tipo C; até então, o leite cru destinado ao beneficiamento desse tipo de leite pasteurizado não possuía parâmetros microbiológicos específicos. De acordo com as novas normas, esse leite deve ser refrigerado já na propriedade e possuir uma contagem de aeróbios mesófilos máxima de $10^{6} \mathrm{UFC} / \mathrm{mL}$, objetivo a ser atingido em diferentes prazos de acordo com a localização geográfica da região produtora (Tabela 1).

Ainda, a denominação "leite tipo C" vigora até data determinada, variável de acordo com a localização geográfica da região produtora $(01 / 07 / 2005$ nas regiões $\mathrm{S}$, $\mathrm{SE}$ e CO e 07/07/2007 nas regiões NE e N), quando será então classificado apenas como leite pasteurizado.

TABELA 1. Requisitos microbiológicos para leite cru refrigerado a serem atingidos em diferentes regiões do Brasil.

\begin{tabular}{|c|c|c|c|c|}
\hline \multirow{6}{*}{ Índice mensurado } & até & de 01/07/2005 até & de 01/07/2008 até & a partir de \\
\hline & 01/07/2005 & 01/07/2008 & 01/07/2011 & 01/07/2011 \\
\hline & (S, SE e CO) & $(\mathrm{S}, \mathrm{SE}$ e CO) & $(\mathrm{S}, \mathrm{SE}$ e CO) & (S, SE e CO) \\
\hline & Até & de $01 / 07 / 2007$ & de $01 / 07 / 2010$ & a partir de \\
\hline & 01/07/2007 & até 01/07/2010 & até 01/07/2012 & 01/07/2012 \\
\hline & $(\mathrm{NE}$ e N) & (NE e N) & (NE e N) & (NE e N) \\
\hline \multirow{3}{*}{$\begin{array}{l}\text { Contagem Padrão } \\
\text { em Placas }\end{array}$} & & \multirow{3}{*}{$1,0 \times 10^{6}$} & \multirow{3}{*}{$7,5 \times 10^{5}$} & $1,0 \times 10^{5}$ \\
\hline & (estab já & & & (individual) \\
\hline & $\begin{array}{l}\text { (estab. Ja } \\
\text { hab.) }\end{array}$ & & & $\begin{array}{l}3,0 \times 10^{5} \\
\text { (coniunto) }\end{array}$ \\
\hline Contagem de & $1,0 \times 10^{6}$ & \multirow{3}{*}{$1,0 \times 10^{6}$} & \multirow{3}{*}{$7,5 \times 10^{5}$} & \multirow{3}{*}{$4,0 \times 10^{5}$} \\
\hline Células & (estab. já & & & \\
\hline Somáticas & hab.) & & & \\
\hline
\end{tabular}

Outra importante norma descrita na IN51 é a regulamentação de conservação, coleta e transporte de leite cru refrigerado, independente do tipo, que deve ser feito a granel. Nas propriedades, o leite deverá ser refrigerado e atingir a temperatura de $4^{\circ} \mathrm{C}$ (tanques de expansão) ou $7^{\circ} \mathrm{C}$ (tanques de imersão), num período não superior a 3 horas após o término da ordenha. Também é prevista a permissão de tanques resfriadores comunitários, que visa atender pequenos produtores. Caminhões-tanque coletam o leite refrigerado e o encaminham a laticínios para processamento. Na recepção dos laticínios, o leite desses tanques não deverá apresentar temperatura superior a $7^{\circ} \mathrm{C}$ (para leite B) ou $4^{\circ} \mathrm{C}$ (para leite $\mathrm{C}$ ).
Outro importante objetivo a ser alcançado é a redução da contagem de células somáticas (CCS), em prazos similares aos estabelecidos para contagem de aeróbios mesófilos (Tabela 1). Todas essas normas representam um importante passo do PNMQL, que buscam a melhoria da qualidade do leite cru produzido no Brasil, resultando num produto final beneficiado de melhor qualidade [14]. Considerando que as regiões $S$, $\mathrm{SE}$ e CO contribuem com a maior parte da produção leiteira no país [15], já em julho de 2005 as propriedades leiteiras dessas regiões deverão apresentar produção com qualidade compatível aos novos padrões de qualidade. Assim, esse trabalho teve como objetivo verificar se o leite cru produzido em quatro áreas de quatro estados grandes produtores de leite no Brasil estaria, nesse momento, em condições de cumprir o estabelecido na IN51, especialmente quanto ao atendimento dos padrões microbiológicos previstos.

\section{2 - MATERIAL E MÉTODOS}

\section{1 - Área de estudo e seleção de propriedades lei- teiras}

Considerando diferenças em práticas de ordenha, 210 propriedades leiteiras foram selecionadas em quatro importantes estados produtores de leite no Brasil: Minas Gerais (MG), Rio Grande do Sul (RS), Paraná (PR) e São Paulo (SP). Todas as propriedades selecionadas podem ser classificadas como pequenas e médias, com produção destinada basicamente a beneficiamento de leite pasteurizado (tipo C), esterilizado (UHT) e derivados, além de comércio informal. As propriedades estavam localizadas nas regiões vizinhas de Viçosa MG (47), Pelotas RS (50), Londrina PR (63) e Botucatu SP (50) (Figura 1).

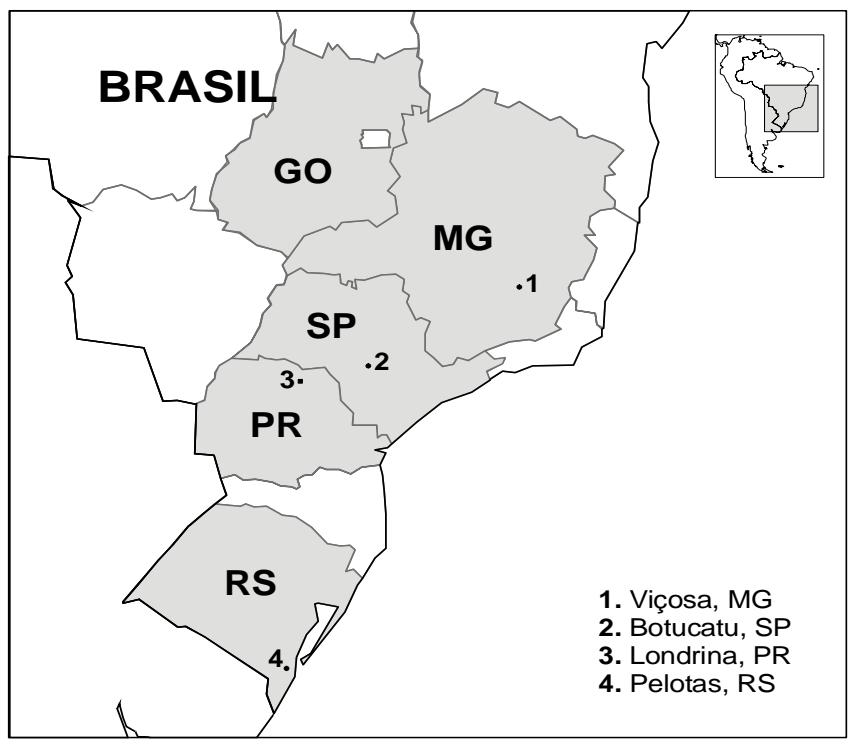

Fonte: IBGE [15]

FIGURA 1. Principais estados produtores de leite no Brasil (GO: Goiás, MG: Minas Gerais, SP: São Paulo, PR: Paraná e RS: Rio Grande do Sul). 
Em cada região a base para coleta das amostras foi um grande laticínio local. Os Departamentos de Assessoria Técnica desses laticínios indicaram produtores que representassem o perfil de produção local. Na região de Londrina a amostragem abrangeu também produtores não ligados ao principal laticínio da região.

Em cada região foi pesquisado o quanto da produção leiteira local está sendo mantida refrigerada e o nível de granelização das indústrias de beneficiamento.

\section{2 - Coleta de amostras e diluições}

Cerca de $100 \mathrm{~mL}$ de leite cru de cada propriedade foram coletados em frascos estéreis. Nas regiões de Viçosa, Pelotas e Londrina a coleta foi feita diretamente nas propriedades, do resfriador ou de latões; na região de Botucatu as amostras foram coletadas na plataforma de recepção de um laticínio, diretamente dos latões. $\mathrm{Na}$ região de Londrina 46 das 63 propriedades não dispunham de resfriador e nas outras regiões todas as amostras coletadas eram refrigeradas. Depois de coletadas, as amostras foram conservadas em recipientes isotérmicos com gelo reciclável e encaminhadas para análises laboratoriais. Cada amostra foi submetida a diluições decimais em solução salina $0,85 \%$ estéril. As análises microbiológicas foram realizadas em até 2 horas após a coleta.

\section{3 - Enumeração de aeróbios mesófilos}

Para enumeração de aeróbios mesófilos, foram utilizadas placas de Petrifilm ${ }^{\mathrm{TM}}$ AC (3M do Brasil Ltda.) $[12,13]$. As diluições $1: 100.000$ e 1:1.000.000 de cada amostra foram semeadas conforme as instruções do fabricante. Após semeadura, as placas foram incubadas a $35^{\circ} \mathrm{C}$ por $48 \mathrm{~h}$, quando as colônias formadas foram enumeradas. O resultado da contagem foi corrigido de acordo com a diluição considerada e expresso em UFC/mL.

\section{4 - Análise dos resultados}

As contagens de aeróbios mesófilos obtidas em cada região foram categorizadas de acordo com os niveis de contaminação. Como parâmetro de comparação, foi considerado o limite de $10^{6} \mathrm{UFC} / \mathrm{mL}$ de aeróbios mesófilos, estabelecida pela IN51 [6].

\section{3 - RESULTADOS E DISCUSSÃO}

Considerando o limite de $10^{6} \mathrm{UFC} / \mathrm{mL}$ de aeróbios mesófilos em leite cru refrigerado [6], 48,57\% das amostras analisadas se apresentaram em desacordo com a IN51. Na Tabela 2 estão apresentados os resultados obtidos por região, considerando os niveis de contaminação por aeróbios mesófilos.

A produção leiteira destinada aos laticínios-base de cada área avaliada era totalmente refrigerada. Entretanto, na região de Londrina a amostragem abrangeu propriedades leiteiras com produção destinada ao comércio informal e a outros laticínios. Considerando as amostras refrigeradas dessa região, 15 (88,2\%) apre- sentaram contagem de aeróbios mesófilos menores que $10^{6} \mathrm{UFC} / \mathrm{mL}$, ou seja, dentro do parâmetro da IN51. Em relação às amostras não refrigeradas, 26 (56,5\%) apresentaram contagens acima de $10^{6} \mathrm{UFC} / \mathrm{mL}$, em desacordo, portanto, à IN51. Na região de Londrina está instalada uma grande usina de beneficiamento que está se adequando as novas normas, porém nessa região (norte do PR) também existem vários pequenos laticínios que absorvem uma parte significativa da produção local, e ainda não exigem padronização na conservação e transporte do leite. Nessa região apenas a produção destinada a essa usina é granelizada.

TABELA 2. Niveis de contaminação por aeróbios mesófilos em leite cru produzido nas 4 regiões estudadas.

\begin{tabular}{|c|c|c|c|c|c|}
\hline Niveis de & Viçosa MG & Pelotas RS & Londrina PR & Botucatu SP & Total \\
\hline contaminação & n (\%) & n (\%) & $\mathrm{n}(\%)$ & $\mathrm{n}(\%)$ & $\mathrm{n}(\%)$ \\
\hline até $10^{3}$ & $02(04,3)$ & $00(00,0)$ & $02(03,2)$ & $00(00,0)$ & $04(01,9)$ \\
\hline $10^{3}-10^{4}$ & $07(14,9)$ & $00(00,0)$ & $03(04,8)$ & $00(00,0)$ & $10(04,8)$ \\
\hline $10^{4}-10^{5}$ & $13(27,7)$ & $09(18,0)$ & $10(15,9)$ & $03(06,0)$ & $35(16,7)$ \\
\hline $10^{5}-10^{6}$ & $15(31,9)$ & $13(26,0)$ & $18(28,6)$ & $13(26,0)$ & $59(28,1)$ \\
\hline $10^{6}-10^{7}$ & $04(08,5)$ & $24(48,0)$ & $10(15,9)$ & $23(46,0)$ & $61(29,0)$ \\
\hline$>10^{7}$ & $06(12,8)$ & $04(08,0)$ & $20(31,7)$ & $11(22,0)$ & $41(19,5)$ \\
\hline$<10^{6}$ & $37(78,7)$ & $22(44,00)$ & $33(52,4)$ & $16(32,0)$ & $108(51,4)$ \\
\hline Total & $47(100)$ & $50(100)$ & $63(100)$ & $50(100)$ & $210(100)$ \\
\hline
\end{tabular}

Os resultados obtidos na região de Londrina evidenciam a importância da refrigeração na conservação da produção leiteira, fator considerado fundamental na IN51 [6]. A importância da refrigeração nas etapas anteriores ao beneficiamento é confirmada pelos resultados encontrados na região de Botucatu. Nessa região, as amostras obtidas foram de produtores que refrigeram a produção leiteira, porém o transporte ainda não é granelizado. Nessas condições, a produção leiteira fica em temperatura ambiente por longos períodos durante o transporte, o que favorece a multiplicação bacteriana e pode explicar a alta freqüência $(68,0 \%)$ de amostras com contagens acima de $10^{6} \mathrm{UFC} / \mathrm{mL}$ de aeróbios mesófilos (Tabela 2). Porém, nessa região devese considerar que a coleta das amostras foi realizada na recepção do laticínio, e não diretamente dos resfriadores de cada propriedade, e também que as amostras apresentaram altas contagens de coliformes totais $(48,00 \%$ das amostras com contagens acima de $10^{3} \mathrm{UFC} / \mathrm{mL}$ - dados não apresentados), o que indica provável contaminação durante a produção. Isso também ocorreu na região de Londrina $(36,4 \%$ das amostras refrigeradas e 69,6\% das não refrigeradas apresentaram contagem de coliformes totais acima de $10^{3} \mathrm{UFC} / \mathrm{mL}$ - dados não apresentados), evidenciando falhas durante a obtenção do leite.

Na região de Pelotas a coleta foi feita diretamente nos resfriadores de cada propriedade. Apesar da produção destinada ao laticínio base dessa área ser totalmente refrigerada e granelizada, observou-se uma fre- 
qüência significativa $(56,0 \%)$ de amostras fora do padrão microbiológico da IN51 (Tabela 2). Esses resultados revelam que apenas a refrigeração na propriedade e transporte pode não são suficientes para garantir a qualidade microbiológica da produção leiteira, sendo necessárias práticas higiênicas durante a ordenha e conservação do leite, como já é descrito no RIISPOA [8] e evidenciado por vários autores [3, 21, 25].

Os objetivos do PNMQL e da IN51 são melhores representados pelos resultados obtidos na região de Viçosa. As amostras dessa área foram obtidas de produtores que abastecem o laticínio da Universidade Federal de Viçosa (UFV), com produção totalmente refrigerada (inclusive com resfriadores comunitários) e transporte granelizado. Desde 1980 a UFV, em parceria com uma empresa privada, desenvolve na região o Projeto de Desenvolvimento da Pecuária Leiteira da Região de Viçosa (PDPL-RV), que visa fornecer auxílio a pequenos produtores da região, auxiliando na adoção de boas práticas e assistência técnica nas propriedades [19]. Todo esse histórico contribui para que $78,7 \%$ das amostras coletadas na área estivessem com contagens abaixo de $10^{6}$ $\mathrm{UFC} / \mathrm{mL}$ de aeróbios mesófilos, o que torna a produção dessas propriedades adequadas aos novos padrões estabelecidos pela IN51. Além de apresentar qualidade microbiológica superior às outras regiões, observou-se a adoção de alternativas a pequenos produtores, como resfriadores comunitários financiados pela UFV.

Pesquisas similares em outras regiões do país mostram resultados semelhantes. BUENO et al. [9] analisaram 20 amostras de leite cru refrigerado no estado de Goiás, atualmente o $2^{\circ}$ maior produtor de leite no Brasil [15], e encontraram 15 (75\%) com contagens acima de $10^{6} \mathrm{UFC} / \mathrm{mL}$. Em outro estudo realizado em Santa Maria, RS [26], observou-se que apenas $17,8 \%$ de 28 amostras de leite cru coletadas na recepção de um laticínio apresentaram contagens abaixo do limite estabelecido pela IN51.

As altas contagens encontradas, mesmo em amostras provenientes de produção refrigerada, podem indicar conservação inadequada do leite. Temperaturas acima de $4^{\circ} \mathrm{C}$ favorecem a multiplicação de microrganismos psicrotróficos [22], que assumem grande importância nesse contexto uma vez que podem ser produtores de proteases e lipases, enzimas que comprometem a qualidade da matéria-prima e do produto beneficiado por serem termo-resistentes [23]. Grande parte das amostras analisadas, independente da região, apresentou lactofermentação caseosa (dados não apresentados), típica de microbiota produtora dessas enzimas. Esse aspecto não é abordado pela IN51, mas pode representar grandes perdas econômicas para a indústria no processamento de derivados, uma vez que a presença dessas enzimas causa baixo rendimento na produção de queijos, além de poder desenvolver sabor amargo e de ranço no produto acabado [23]. Essa evidência pode sugerir que a enumeração de psicrotróficos, considerando os novos padrões de conservação e transporte do leite, pode ser também um importante indicativo da qualidade do leite.

\section{4 - CONCLUSÕES}

Os resultados obtidos nesta pesquisa permitem concluir que algumas áreas podem enfrentar dificuldades de adequação às normas estabelecidas pela IN51, já que os resultados mostraram uma alta freqüência de amostras com elevados niveis de contaminação por aeróbios mesófilos. Também fica evidente que a adoção de resfriamento da produção nas propriedades e a granelização da coleta são importantes medidas para garantir a qualidade microbiológica do leite, como pretendido pelo PNMQL. Entretanto, a adoção isolada dessas medidas não é suficiente para a produção de leite de boa qualidade microbiológica, sendo de grande importância o desenvolvimento de programas regionais de assistência à produtores leiteiros, a exemplo do PDPLRV. Portanto, a integração entre produtores, indústria, centros de pesquisa e órgãos fiscalizadores é fundamental para a produção de um leite de qualidade, capaz de concorrer no mercado internacional.

\section{5 - REFERÊNCIAS BIBLIOGRÁFICAS}

[1] BELOTI, V.; BARROS, M. A. F.; FREIRE, R. L.; NERO, L. A.; SOUZA, J. A.; NAVARRO, I. T. Evaluation of physicalchemical and microbiological characteristics of pasteurized milk types commercialized in Londrina city, Paraná, Brazil. Epidemiologie et Sante Animale, n..311, p.04.A.50, 1997.

[2] BELOTI, V.; BARROS, M. A. F.; SOUZA, J. A.; NERO, L. A.; SANTANA, E. H. W.; BALARIN, O.; CURIAKI, Y.. Avaliação da qualidade do leite cru comercializado em Cornélio Procópio, Paraná. Controle do consumo e da comercialização. Semina: Ciências Agrárias, v.20, n.1, p.12-15, 1999.

[3] BELOTI, V.; SANTANA, E. H. W.; FAGAN, E. P.; BARROS, M. A. F.; PEREIRA, M. S.; MORAES, L. B.; GUSMÃO, V. V.; MATTOS, M. R.; NERO, L. A.; VACCARELLI, E. R.; SILVA, L. H. C.; MAGANANI, D. F.; HAGA, M. M. Principais pontos de contaminação na produção leiteira e implementação de boas práticas. II Congresso Panamericano de Qualidade do Leite e Controle de Mastite, Ribeirão Preto, SP, 24 a 27 de novembro de 2002.

[4] BRASIL. Portaria $n^{\circ} 166$, de 05 de maio de 1998. Cria grupo de trabalho para analisar e propor programa e medidas visando ao aumento da competitividade... Diário Oficial da União, Brasília, p.42, 06 maio 1998. Seção 1.

[5] BRASIL. Portaria $n^{\circ}$ 56, de 107 de dezembro de 1999. Submete a consulta pública os regulamentos técnicos de padrão de identidade e qualidade de leite... Diário Oficial da União, Brasília, p.34, 08 dez. 1999. Seção 2 .

[6] BRASIL. Instrução Normativa $n^{\circ} 51$, de 20 de setembro de 2002. Aprova os regulamentos técnicos de produção, identidade e qualidade do leite tipo... Diário Oficial da União, Brasília, p.13, 21 set. 2002. Seção 1.

[7] BRASIL, Resolução n 3.088, de 25 de junho de 2003. Dispõe sobre o programa de incentivo à mecanização, ao resfriamento e ao transporte granelizado... Diário Oficial da União, Brasília, 26 jun 2003.

[8] BRASIL. Decreto-Lei $n^{\circ}$ 30.691, de 29 de março de 1952. Aprova o novo Regulamento da Inspeção Industrial e 
Sanitária de Produtos de Origem Animal. Diário Oficial da União, Rio de Janeiro, p.10.785, 07 jul. 1952.

[9] BUENO, V. F. F.; MESQUiTA, A. J.; NICOLAU, E. S.; MANSUR, J. R. G.; NEVES, R. B. S. Parameters of microbiological quality of raw milk and water in dairy farms in Goiás state - Brazil. II Congresso Panamericano de Qualidade do Leite e Controle de Mastite, Ribeirão Preto, SP, 24 a 27 de novembro de 2002.

[10] CERQUeIRA, M. M. O. P.; SOUZA, M. R.; LEITE, M. O.; BARBOSA, E. M.; ALMEIDA, M. R. Características microbiológicas de leite cru e beneficiado em Belo Horizonte (MG). Arquivo Brasileiro de Medicina Veterinária e Zootecnia, v.46, n.6, p.713-721, 1994.

[11] FRANCO, R. M.; CAVALCANTI, R. M. S.; WOOD, P. C. B.; LORETTI, V. P.; GONÇALVES, P. M. R.; OLIVEIRA, L. A. T. Avaliação da qualidade higiênico-sanitária de leite e derivados. Higiene Alimentar, v.14, n.68/69, p.70-77, 2000

[12] GINN, R. E.; PACKARD, V. S.; FOX, T. L. Evaluation of the $3 \mathrm{M}$ dry medium culture plate (Petrifilm ${ }^{\mathrm{TM}} \mathrm{SM}$ ) method for determining numbers of bacteria in raw milk. Journal of Food Protection, v.47, n.10, p.753755, 1984.

[13] GINN, R. E.; PACKARD, V. S.; FOX, T. L. Enumeration of total bacteria and coliforms in milk by dry rehydratable film method: collaborative study. Journal of AOAC, v. 69, p.527-571, 1986.

[14] GUIMARÃES, R. Importância da matéria-prima para a qualidade do leite fluido de consumo. Higiene Alimentar, v.16, n.102/103, p.25-34, 2002.

[15] IBGE - Instituto Brasileiro de Geografia e Estatística. Consultado na INTERNET em março 2004. http:// www.ibge.gov.br

[16] LOURENÇO, L. F. H.; SILVA, M. S. S. Análises físicoquímica e microbiológica como indicadores da qualidade do leite cru comercializado no município de Castanhal/Pará. XVII Congresso Brasileiro de Ciência e Tecnologia de Alimentos, Fortaleza, CE, 8 a 10 de agosto de 2000.

[17] MOURA, S. M.; DESTRO, M. T.; FRANCO, B. D. G. M. Incidence of Listeria species in raw and pasteurized milk produced in São Paulo, Brazil. International Journal of Food Microbiology, v.19, p.229-237, 1993.

[18] NADER FILHO, A.; ROSSI JUNIOR, O. D. Evaluation of microbiological characteristics of type $\mathrm{C}$ milk and of plastic containers used in packaging in processing plant in São Paulo state, Brazil. Revista de Microbiologia, v.20, n.3, p.261-266, 1990.

[19] PDPL-RV - Programa de Desenvolvimento da Pecuária Leiteira da Região de Viçosa. Consultado na INTERNET em março 2004. http://www.ufv.br/pdpl

[20] PEREIRA, M. A.; RODRIGUES, K. L.; MOREIRA, C. N. Escherichia coli verotoxigênica em leite cru e beneficiado em Pelotas, RS. XXI Congresso Brasileiro de Microbiologia, Foz do Iguaçu, PR, 21 a 25 de outubro de 2001.

[21] POIATTI, M. L.; PARO, F. M.; SCHOCKEN, P. F. L.; SCHOCKEN-ITURRINO, R. P. Características microbiológicas do leite tipo B "in natura" e pasteurizado em diferentes pontos do fluxograma de beneficiamento. $\mathbf{x x}$ Congresso Brasileiro de Microbiologia, Salvador, BA, 24 a 28 de outubro de 1999381.

[22] PRATA, L. F.; FUKUDA, S. P.; MARTINS, L. S.; FIGUEIREDO, S. F. Influência da coleta a granel, em dias alternados, sobre a qualidade do leite cru mantido sob refrigeração na fazenda. Higiene Alimentar, v.10, n.45, p.29-34, 1996.

[23] SANTOS, E. S.; CARVAlho, E. P.; ABREU, L. R. Psicrotróficos: conseqüências de sua presença em leites e queijos. Boletim da SBCTA, v.33, n.2, p.129138, 1999.

[24] SILVEIRA, N. V. V.; SAKUMA, H.; DUARTE, E. L. Avaliação das condições físico-químicas e microbiológicas do leite pasteurizado consumido na cidade de São Paulo. Revista do Instituto Adolfo Lutz, v.49, p.19-25, 1989.

[25] VERAS, J. F.; RAPINI, L. S.; COUTO, I. P.; MENDONÇA, A. H.; SILVA, A. O.; CERQUEIRA, M. M. O. P.; SOUZA, M. R.; PENNA, C. F. A. M. Monitoring of the raw milk quality and sanitation of teats and dairy equipment. II Congresso Panamericano de Qualidade do Leite e Controle de Mastite, Ribeirão Preto, SP, 24 a 27 de novembro de 2002.

[26] VIANA, L. R.; HENZEL, A.; SPRICIGO, D. A.; LOGUERCIO, A. P.; WITT, N. M.; VARGAS, A. C. Qualidade do leite in natura recebido pela usina escola de laticínios da UFSM. XXIX Congresso Brasileiro de Medicina Veterinária, Gramado, RS, 10 a 14 de outubro de 2002.

\section{6 - AGRADECIMENTOS}

Apoio financeiro: FAPESP (bolsa de doutorado de L.A.Nero, 01/13076-8) e 3M do Brasil Ltda. 